\title{
Maintaining science culture in Japan
}

Two of Japan's government agencies are set to be merged in an attempt to raise the country's scientific standards. But unless a 'bottom-up' approach to science is adopted, the culture of basic research may be damaged.

\section{Minoru Oda}

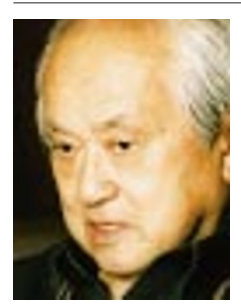

In a planned reorganization of its science-related government agencies, Japan is to merge the Ministry of Education, Science, Sports and Culture (Monbusho) with the Science and Technology Agency (STA). It is hoped that this will strengthen science in higher education and bring healthier practices and greater flexibility to the funding system of the education ministry. But there is a danger that the culture of basic research cultivated in Japanese academic institutions in the past century will be lost with the introduction of 'top-down' science administration.

The roots of this culture can be traced back to the Meiji restoration near the end of the nineteenth century, when Japan's first university, modelled on European (particularly German) lines, was established in Tokyo as the first of seven 'Imperial' universities. Although some Japanese scientists gained international repute in those early days, the overall academic level of the scientific community was far below that of the West: most scientists trained in Europe but retained the intellectual values of the old Edo Era culture.

In the early twentieth century, Japan changed from being an agricultural society to an industrial one. Its isolation from the West during the First World War led to the establishment in 1917 of the Institute of Physical and Chemical Research (RIKEN). It was set up as a semi-private organization with a donation from the Imperial family in the belief that Japan's survival depended on the promotion of basic research in science and technology in organizations run in parallel with the Imperial universities.

After the Second World War, the centre of scientific research had become the United States rather than Europe, and Japanese intellectuals were shocked to discover how far they had been left behind. Under US influence during Japan's occupation, the education system was extensively changed. The concept of the seven Imperial universities, based on classical European academic ideals, was replaced with 'democratic' and 'average' university education for the masses. Hundreds of new national and private universities raised the standards of education of 'blue-collar' workers and boosted Japanese industry. And in a backlash against the previous era of militaristic interference, academic freedom was also strengthened.
But in this rapid expansion, funding for university research was spread far too thinly, and there was a need for more focused investment. So the National Research Institutes for Joint University Use, including the Institute of Space and Astronautical Science and the National Laboratory for High Energy Physics, were established. Today's 14 member bodies are important for the cultivation and coordination of a variety of disciplines.

The Ministry of Education has come to understand that basic science is a valuable cultural asset. It has also started to listen to academics, adopting a 'bottom-up'approach to policy formation. But other science-related government ministries and agencies, such as the STA, adopt a 'top-down' approach. They view science as the basis of technology (and so industry) rather than as part of culture. That 'science' and 'technology' are separate concepts based on different philosophies and strategies is often overlooked by bureaucrats, politicians and the public.

The exception is RIKEN, now under the administration of the STA, which has retained a spirit of autonomy and flexibility. A potential benefit of the merger of the STA and Monbusho is that RIKEN could be adopted as a model for research organizations outside the universities, such as the National Research Institutes for Joint University Use, as its founders intended 80 years ago.

But there is also a danger that the 'topdown' approach of the STA could destroy the freedom and autonomy of research institutes under Monbusho. Consider for example the Institute of Space and Astronautical Science (ISAS) under Monbusho, and the National Space Development Agency (NASDA) under the STA. Politicians and bureaucrats might think it would make sense to merge these two space agencies when the STA and Monbusho merge. After all, what other country maintains two space agencies?

But here we see the contrast in their management styles. ISAS, an offshoot of the University of Tokyo, is an academic research organization devoted to astrophysics, space science and technology. It is small, but flexible

It is hoped that the STA will bring much-needed new funds to basic science. But a flexible 'bottom-up' approach will be essential and autonomous. Space programmes are run by scientists and engineers, from proposal to implementation, including the design and production of satellites and launch vehicles, and launch and flight operations. It provides opportunities for research to the space-science community worldwide.

NASDA, on the other hand, is an applications-oriented agency that implements Japan's national space policy under the 'topdown' guidance of the STA. Its objectives reflect domestic and international policy objectives, such as establishing the infrastructure of Japan's space activity and participating in the Space Station Programme. The merger of ISAS and NASDA or the National Aerospace Laboratory might provide Japan's space programme with greater flexibility in the scale and budget of its operations, but the academic pursuit of space research could be overwhelmed by other forces with stronger and more immediate political appeal.

Indeed, according to one US astrophysicist, the idea that the merger will make Japanese space policy more efficient is too naive. He points out that many US and European researchers envy Japan's dual system and praise the accomplishments of ISAS. But they have been quick to emphasize the institute's limited budgets and facilities. For example, on visiting the Halley Mission Control Center at ISAS in 1986, someone from the US space agency NASA remarked: "we were encouraged that planetary exploration may still be possible with such limited and poor facilities". Another recent visitor to ISAS commented that the world's first spacebased satellite for Very Long Baseline Interferometry developed by the institute with a large deployable antenna was like "Marilyn Monroe wearing vagabond's rags”.

These statements highlight the modest support for basic science in Japan. Although the government enacted the Basic Science and Technology Law in 1996 to promote science and technology, only applications-oriented research fields have so far benefited. In fact the budgetary ceilings for the next fiscal year, which begins on 1 April, for institutes such as ISAS and the National Astronomical Observatory have been drastically lowered.

It is hoped that the merger of Monbusho with the STA, which is faring better financially under the law, will bring much-needed new funds to basic science. But a flexible 'bottom-up' approach will be essential. $\square$ Minoru Oda, a former director general of ISAS and former president of RIKEN, is at the Tokyo University of Information Science, Yato-cho, Wakaba, Chiba-shi265, Japan. 